not absolutely straight lines, it does not necessarily follow that the sum of its angles is equal to $\pi$ : for Euclid himself is quite ready to admit that. No: Prof. Clifford must have meant that those three sides, though absolutely straight to us, creatures who can only imagine a homaloidal trid mensional space, are curved in a sense (thanks to a fourth dimension) which vitiates the Euclidian law.

Of cour-e he may disclaim this interpretation: or he may assert that in the case supp ised the three sides are both straight and curved, or neither straight nor curved, if such be his view. But until I see his disclaimer I shall hold that he meant to suggest to his aud e ice that straight lines (proved to be so by the standard of straightness which is alone imaginable by creatures constituted as we are) are in another sense really curved, and as such afford an observable exception to the Euclidian Law. Now I say that, constituted as we are, we could have seen straight lines only as straight, and therefore we simply could not see those sides otherwive than as verifying that Law; and so we could never bring to the test of observation the question raised by the great qua ernion of geometers; and therefore must for ever remain in ahsolute ignorance whether the space, in which we "live and move and have our being," be (in another relation) something different from what we find it to be in relation $t$, our faculties.

Athenæum Club, Feb. 8

\section{Earthquake in Pembrokeshire}

I HAVE received a letter from the west part of Pembrokeshire, dated February 3, from which the following is an extract :- -

"Last Siturday, at 7 A.M., my bed shook twice under me; and at the same time the servant went into the dining-room, the fire-irons rattled and the room shook; an hour later, - - 's bed shook twice."

I do $n$, t know whether any notice has been taken of the occurrence elsewhere. I have paid some attention of late years to the indications of earthquakes in this neighbourhood, and am inclined to think that slight tremulous movernents take place more frequently than may have been supposed or recorded. They would naturally be unnoticed in the daytime, and their det-ction would depend upon accidental wakeiulness at night.

Hard wick Vicarage, Feb. 8

T. W. WEBB

\section{Meteorology of the Future}

IT is with some satisfac ion that I have read in NATURE of Necember 12,1872 , the very interesting paper of Mr. J. Norman Lockyer, entitled "Meteorology of the Fu ure," giving adhe-ion and the support of his name to the discovery of Mr. C Meldrum, of a cycle of II years in the recurrence of the maximum of cyclones and rainfall in the southern hemisphere; a cycle corresponding with that already recognied in the maximum of sunspots. But I have been somewhat sarprived to see that my name sas not been mentioned by $\mathrm{Mr}$. Lockyer in reference to $\mathrm{Mr}$. Meldrum's paper, as I h ive also published a paper on the connec ion of sun-spots with rainfalls, storms, cyclones, \&c, prior to the first paper of Mr. Meldrum, which appeared in NATuRE, October 24, 1872 . Thinking that my paper bas escaped your notice, and trusting that you might have some interest to see it, I take the liberty to forward it to you with this same mail. It was published in the Boston Daily Advertiser, November 2, 1871 . Over a year has elapsed since its putlicatiun, and few are the days on which I had no opportunity of seeing the sun and scrutinising its spots with especial care, with the aid of telescope and spectroscope; and to-day I do not see the nec-ssity of changing a word of the conclusions which I had come to in that paper. Only it appears that, in addition to the laws which I have drawn out, appears that, in addition will have to be taken in consideration as a cumplicating element; as it seems that the conjunction and opposition have a tendency to increase the influence of the spots on our atmosphere, while the quadrature diminishes it in a certain measure. I could make some other remarks taken from my greater experience on the subject, but they are of secondary importance, and I will wait for another opportunity to publish them.

Perhaps I did not guarả myself sufficiently in my paper, and have not explained with a sufficient amount of clearness, that though the effect of sun-spots on the weather is general all over the globe, yet the result cannot be expected to be absolutely the same; as local causes, very numerous, like mountain chains, forests, rivers, coasts, oceans, and climates, have an independent influence on the distribution of rains and the direction of winds, \&c. But local causes are of a secondary order, and will be easily determined when once we are sure that the primary cause of atmospheric disturbances is to be found in the solar spots

Cambridge, Mass., Jan. 27

L. TROUVELOT

\section{Deep Wells}

SINCE the question of the supply of water to deep wells was touched upon in NATURE (vol. vii. p. 177), in connection with the rainfall of 1872 , I have been in hopes ta ch week of seeing the sub. ject thoroughly and scientifically discu $s: d$. It will be recollected that whle we were all sneezing and spluttering, and thoughtiessly complaining of the long-continued wet, Mr. Bailcy Denton deprecated the premature interference of the Archbishop of Canter. bury with the rain, on the ground that the deep wells were not yet filled. This raised a great deal of discussion; people lost their tempers over the rain; and the country seemed to be divided into three bitterly hustile parties-the supporters, the opponents, and the suppliants of Providence. But still the geologists held aloof, and no one even answered the question, "What is a deep well?" but continued to talk as if wells were divided into two classes, deep and shallow, by a hard and fast line.

I therefore venture to hope that some geologist will take up the question in your columns, and give us a few facts instead of opinions. Meanwhle, I will state the ca-e as it appears to me. With the exception of chalk and limestone formations, deep wells are, I believe, unknown in hills. In the side of a hill water comes naturally to the surface in a spring. Wells are only required-or, at all events, deep ones-at a distance from hills. They derive their water from water-bearing strata supplied in all cases either directly from hills, or indirectly from hills through the leakage of river-beds. No amount of rain falls upon culitvated, and therefore comparatively low-lying, land in Europe, sufficient to penetrate to even a shallow well through the earth imnediaiely around it. This, at least, I presume to be the case, for 33 per cent. of their own bulk may be taken as an average amount of water for average soils to be able co retain and hold, so that if a well were $15 \mathrm{ft}$. deep to the top of the water it could not be affected by less than $5 \mathrm{ft}$. of rainfall, and when we deduct the enormous proportion of the $5 \mathrm{ft}$. that would be lust by evaporation and intercepted by vegeration, it is manifest that even $5 \mathrm{ft}$. of rain could not penetrate $15 \mathrm{ft}$. through any ordinary average soil. How, then, could any rainfall penetrate to a "deep" well of, say 100 or $200 \mathrm{ft}$, in depth?

Feb. 9

W. HOPE

THE GRESHAM LECTURES ON PYYSIC

THE Hilary Term Course of Lectures on Physic were delivered at the Gresham College, Basinghall Street, by Dr Symes Thompson, on the evenings of the I 7 th and 18 th ult., and the subject of the discourses upon this occasion was the important and interesting one of Contagious and Infectious Diseases. The professor started on his career of familiar explanation by describ ng two recent instances of outbreak of infectious disease in rural districts, in which the introduction and march of the fell agent of communication through the ranks of the small community could be distinctly traced. In the one case, the infection of scarlet fever was brought to the village of Flindon, in Hampshire, by a girl who came from Worthing, and served in a small general shop which was resorted to by all the villagers. Only two houses in the village that had children in them, escaped from the disease. In the other case, enteric fever was taken to Whitchurch, in Hampshire, by a young woman from Basingstoke, who returned to Basingstoke to die, after only six days' sojourn in Whitchurch. The fever, nevertheless, spread from the house in which she stayed, and within the next seven months there were seventy cases of enteric fever in a small community numbering only 1,450 people. The instance at Whitchurch acquired especial importance and interest, because it was made the ground for an investigation and report by the Local Government 